\title{
Feature Extraction of ECG signal using Meyer Wavelet Transform
}

\author{
SK. Piramu Preethika, R. Gobinath
}

\begin{abstract}
Humans suffered with heart related issues in this century due to the poor and improper regular routines which causes a major damage to their entire life. This paper deals with cardiovascular arrhythmias prevention and control by the usage of Electrocardiogram. Cloud storage is utilized for storing the voluminous data of Electrocardiogram details of patients. The collected raw data is pre-processed using the Meyer wavelet transform. It is a kind of a continuous wavelet, which is applied in several cases especially in adaptive filters multi-fault classification. The features extracted are amplitude, age, sex, RR speed and Medicine.These are considered as the information of each data packets that are stored in cloud and later it is transmitted to healthcare centres and physicians for diagnosis and appropriate treatment.
\end{abstract}

Keywords:Electrocardiogram (ECG),cardiovasculardiseases (CVD); Meyer wavelet transform (MVT)

\section{INTRODUCTION}

In the fast-moving world all are in a hurry to move here and there to achieve their dreams comes to true. No limits to reach their goals, sky is the limit also exceeds nowadays beyond the sky is also possible.More work pressure and thirst to the unfulfilled desires gives the stress to the humans. Due to this anxiety level increased and discomfort opens the path of cardiac arrest in elderly people. A strictly week routine of attitude towards meal intake and meals at the same time (breakfast at $7 \mathrm{am}$, lunch at 12 noon, and dinner at $7 \mathrm{pm})$ followed to have that entirely differs from our grandparents. So, our body was habituated to expect food, this kind of control lend a hand to preserve waistlines slim. In the modern day, allof us lost their well-organized approach to meals and skip the 3-square-meal-a-day rule. Skipping or delaying morning food, junk routines like fried crispy followed by chilled beverages or numerous cups of coffee a day are perceptions that we deviate from our grandparents, this affects our bodyhealth.Grandparents had a authoritarian schedule to what they ate on which day of the week. Now the family ate a baked dinner on Sunday, pursed leftover cold meat on the following day, this is our custom and it leads to unhealthy eating habit. Modern day microwave cooking and ready to eat meals replaces our traditional cooking.

As per world Health Organization (WHO) Cardiovascular diseases (CVDs) every time seize the life of 17.9 million people, universal death rate reached to $31 \%$.-

Revised Manuscript Received on July 08, 2019.

SK. Piramu Preethika *, ${ }^{1}$ Research Scholar, Department of Computer Science, VISTAS.E-mail: preethikamanikandan@ gmail.com

R. Gobinath, Assistant Professor, Department of Computer Science, VISTAS, Chennai. which is the mark of beginning to sensitivity in heart attacks and strokes - are usage of tobacco, Damaging diet \& polluted environment, corporal inactivity and the consumption of liquor eliciting these diseases[1]. These successively show up in individuals as raised pressure level, elevated glucose and overweight and blubber, risks damaging to sensible heart health.

Stress and tension, diet, smoking, drinking, obesity, no physical activity, some prescription medications, uncontrolled diabetics latest life style like all others are the road map to Sudden Cardiac Arrest (SCA) and it happens without any caution. Some people experience irregular heart beat which may be too slow, or too fast is called as Arrhythmias or cardiac dysrhythmia. In the information era everything is reachable and accessible through internet and mobile.

\section{ECG Waveform}

Electrocardiogram (ECG) is foremost test to predict a cardiac arrhythmia.ECG stands for electrocardiogram: electro = electrical; cardio $=$ heart; gram $=$ recording. $[2][4]$. The electrocardiogram (ECG) shows the graph of the bio-potential activity of the heart over a time constraint which is recorded by the electrodes connected to the body either using three leads or twelve leads attached to the surface of the skin. [2].

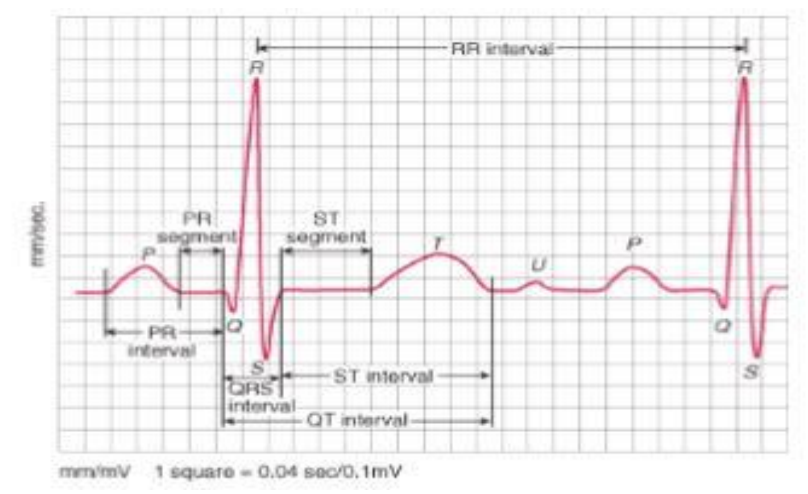

Figure 1 Normal ECG pattern [3]

A normal ECG pattern having the parts as $\mathrm{P}, \mathrm{QRS}$

Curve and also a $\mathrm{T}$ wave as shown in the above Figure 1. Human heart's stimulating activity of depolarization and repolarization of the atrial and ventricular chambers of the heart is recorded as an ECG.Depolarization is the sudden arrival of cations when the membrane becomes leaky, and repolarization is the recovery phase of the ion concentrations returning to normal. A particular ECG cycle symbolizes the successive depolarisation/repolarisation and ventricular depolarisation/repolarisation 
accompanied with each heartbeat and those will be written off as peaks and troughs features of waveform [3] [4].

\begin{tabular}{|l|l|l|l|}
\hline \multicolumn{4}{|c|}{ Amplitude(mV) } \\
\hline \hline P WAVE & $\begin{array}{l}\text { R } \\
\text { WAVE }\end{array}$ & Q WAVE & T WAVE \\
\hline $0.25 \mathrm{mV}$ & $\begin{array}{l}1.60 \mathrm{~m} \\
\text { V }\end{array}$ & $\begin{array}{l}\text { 25\% of } \mathrm{R} \\
\text { wave }\end{array}$ & 0.1 to $0.5 \mathrm{mV}$ \\
\hline
\end{tabular}

\begin{tabular}{|l|l|l|l|}
\hline $\begin{array}{l}\text { PR } \\
\text { INTERVAL }\end{array}$ & $\begin{array}{l}\text { QT } \\
\text { Interval }\end{array}$ & ST interval & QRS Interval \\
\hline $0.12 \mathrm{sto}$ & $0.35 \mathrm{~s}$ to & $0.05 \mathrm{~s}$ to & $\begin{array}{l}0.06-0.12 \\
0.15 \mathrm{~s}\end{array}$ \\
$0.20 \mathrm{~s}$ & $0.44 \mathrm{~s}$ & $0.09 \mathrm{~s})$ \\
\hline \multicolumn{4}{|c|}{ Duration (Seconds) } \\
\hline
\end{tabular}

Table 1 Normal ECG Waveform Parameters (Amplitude (mV)) and duration (seconds)

\section{Arrhythmia Types}

Cardiac Arrhythmia classified into so many categories. And it will be classified from the beat style of ECG signal. For a normal healthy person 60 beats per minute $(\mathrm{Bpm})$ is the standard reading while resting. A person having too fast beat ranging from 120 to 250 had an arrhythmia called as Tachycardia. The sub type of tachycardia are Atrial or Supraventricular, Sinus, VentricularCardia. If the beat style is too slow then it is called as Bradycardia and it has less than $60 \mathrm{Bpm}$.Irregular beat style having two sub divisions called Flutter \& Fibrillation in which the extreme end is $600 \mathrm{Bpm}$ and above sometimes causes Sudden Cardiac Arrest(SCA).Following table shows ECG beat style arrhythmia classification

\section{REVIEW OF LITERATURE}

Sadiq and Nidhal H. Shukr et al. presented a ID3 classification algorithm to categories the arrhythmias. They applied discrete wavelet transform technique for noise filtering and included Interactive Dichotomizer 3 (ID3) algorithm to select the three features [4].

Acharya, U. Rajendra et al., stated that aged peoples grow weaker and get suffered with cardiac arrhythmias compared to younger ones. Elderly population having the life threatened arrhythmias like atrial fibrillation (A-Fib), atrial flutter (AFL), and ventricular fibrillation (V-Fib) due to the abnormal heartbeat [5].

Chen et al. presented a novel move towards electrocardiogram in which projected and dynamic features combined. Projected features are derived from a random projection matrix, during which every column is normalized, and every row is reworked by discrete cosine transform (DCT).In the second part they focused on three weighted RR intervals which named as previous RR, post $\mathrm{RR}$, and local RR intervals and declared as dynamic features. This minimizes the energy by compressed sensing as opposed to Nyquist sampling without rebuild to cluster heartbeats [7].

Ibrahim and Mohamed Ismail Owi et al., present a robust implementation algorithm to discriminate between normal sinus rhythm and given focus to three types of arrhythmia namely atrial fibrillation (AF), ventricular fibrillation (VF), and supra ventricular tachycardia (SVT) which were accumulated from physio net database. This is attained by capturing the main features that contain both rate of recurrence and locality of the signal through discrete wavelet transform, pursued by principal component analysis on each decomposed point. Features were reduced through statistical analysis as an input to support vector machine with optimized parameters [8]

Serkan, Turker and Moncef et al. projected a fast and precise patient-specific adaptive execution of I-D conventional neural network to detect ventricular ectopic beats and supraventricular ectopic beats in which computational efficiency achieved.Datasets retrieved using MITBIH database.Future work will be focused on hardware implementation [9].

\section{Methodology}

\section{Wavelet:}

Wavelet is a wave like oscillation with amplitude that begins at zero. It is specially designed to assess signal processing. Wavelet is analogous to Fourier transform and splits a signal into its vital parts for analysis. Fourier transform decompose the series of sine waves of different frequencies whereas wavelet transform divides the signal into scaled and shifted forms of mother wavelet which is called as 'wavelet'. Dilation process is admitted to the mother wavelet to compute the wavelet coefficients [16].

\section{Features of wavelet:}

avelets analyses data fully

$$
>
$$

athematical tool used to extract data from Audio signals and images

$>$

pplied in digital signal processing

omplementary wavelets decompose data without overlapping \& used in compression/decompression

$>$ Examines non-steady signals like ECG

$>$ Signal decomposed to multi-resolution units

\subsection{Existing Methodology}

\section{A. Continuous Wavelet Transform (CWT)}

Continuous wavelets are used for both wavelet decomposition and composition transforms.Both time and frequency analysis performed using Continuous Wavelet transform and separates continuous function into wavelets.CWT was developed to conquer the resolution difficulty in STFT. CWT is shown by Eq. (1).

$$
\mathrm{W}_{\mathrm{s}}(\mathrm{a}, \mathrm{b})=\frac{1}{\sqrt{a}} \int_{-\infty}^{\infty} f(t) \varphi *\left(\frac{t-b}{a}\right) d t
$$

The most significant function of the mother wavelet is to provide a base function to produce the daughter wavelets [10]. To recover signal, the first inverse continuous wavelet transform can be exploited and is represented by Eq. (2)

$$
f(t)=\frac{1}{c} \iint_{-\infty}^{\infty} \text { Ws }(a, b) \varphi\left(\frac{t-b}{a}\right) \frac{d a}{a^{2}} d b
$$




\begin{tabular}{|c|c|c|c|c|c|}
\hline $\begin{array}{r}\text { EC } \\
G^{\text {bea }} \\
t \text { style }\end{array}$ & $\begin{array}{c}\text { Typ } \\
\text { e name }\end{array}$ & \begin{tabular}{l}
\multicolumn{1}{c}{ Bp } \\
m \\
(beats \\
per \\
minut \\
e)
\end{tabular} & $\mathrm{e}^{\text {Featur }}$ & $\begin{array}{l}\text { Symp } \\
\text { toms }\end{array}$ & $\begin{array}{l}\text { Treat } \\
\text { ment }\end{array}$ \\
\hline $\begin{array}{l}\text { No } \\
\text { rmal }\end{array}$ & $\begin{array}{l}\text { Heal } \\
\text { thy }\end{array}$ & $\begin{array}{l}60- \\
100\end{array}$ & regular & al norm & $\begin{array}{c}\text { Not } \\
\text { required }\end{array}$ \\
\hline $\begin{array}{c}\text { To } \\
\text { o Fast }\end{array}$ & $\begin{array}{r}\text { Tach } \\
\text { ycardia } \\
\text { a)At } \\
\text { rial/sup } \\
\text { raventr } \\
\text { icular } \\
\text { b)Sinus } \\
\text { c)Vent } \\
\text { ricular }\end{array}$ & $\begin{array}{r}120 \\
-250\end{array}$ & \begin{tabular}{l}
\multicolumn{1}{c}{$\mathrm{RR}$} \\
interval \\
$<0.6 \mathrm{~s}$
\end{tabular} & $\begin{array}{l}\text { Strok } \\
\text { e } \\
\text { Blood } \\
\text { clot } \\
\text { Unex } \\
\text { pected } \\
\text { death }\end{array}$ & $\begin{array}{l}\text { Vagal } \\
\text { manever } \\
\text { s } \\
\text { Medic } \\
\text { ations } \\
\text { Bypas } \\
\text { s } \\
\text { Surgery }\end{array}$ \\
\hline $\begin{array}{l}\text { To } \\
\text { o } \\
\text { Slow }\end{array}$ & $\begin{array}{r}\text { Brad } \\
\text { ycardia }\end{array}$ & $\begin{array}{l}\text { Less } \\
\text { than } \\
60\end{array}$ & \begin{tabular}{l}
\multicolumn{1}{c}{$\mathrm{RR}$} \\
interval > \\
$1 \mathrm{~s}$
\end{tabular} & $\begin{array}{l}\text { Chest } \\
\text { pain } \\
\text { Tired } \\
\text { ness } \\
\text { Palpit } \\
\text { ations } \\
\text { Fainti } \\
\text { ng } \\
\text { sweati } \\
\text { ng }\end{array}$ & $\begin{array}{l}\text { Pacem } \\
\text { aker }\end{array}$ \\
\hline $\begin{array}{l}\text { Irre } \\
\text { gular }\end{array}$ & $\begin{array}{l}\text { Flutt } \\
\text { er }\end{array}$ & $\begin{array}{r}250 \\
-350\end{array}$ & $\begin{array}{l}\text { a)In } \\
\text { Upper } \\
\text { chamber } \\
\text { irregular } \\
\text { pattern } \\
\text { b)out } \\
\text { of } \\
\text { synchron } \\
\text { y with } \\
\text { lower } \\
\text { chamber }\end{array}$ & $\begin{array}{l}\text { Stron } \\
\mathrm{g} \\
\text { contracti } \\
\text { on \& } \\
\text { Too } \\
\text { fast beat } \\
\text { in elders } \\
\\
\text { Angin } \\
\text { a Dizzi } \\
\text { ness } \\
\text { Synco } \\
\text { pe } \\
\text { Weak } \\
\text { ness } \\
\text { breath } \\
\text { lessness }\end{array}$ & $\begin{array}{l}\quad \text { Cathet } \\
\text { er } \\
\text { ablation( } \\
\text { like } \\
\text { pacemak } \\
\text { er }\end{array}$ \\
\hline $\begin{array}{l}\quad \text { Ear } \\
\text { ly } \\
\text { Heart } \\
\text { beat }\end{array}$ & $\begin{array}{l}\quad \text { Pre } \\
\text { mature } \\
\text { Contra } \\
\text { ction }\end{array}$ & $\begin{array}{l}\text { Ski } \\
\text { pped } \\
\text { beat }\end{array}$ & $\begin{array}{l}\text { Differe } \\
\text { nt QRS \& } \\
\text { Twave }\end{array}$ & $\begin{array}{l}\text { Palpit } \\
\text { ations } \\
\text { Light- } \\
\text { headedn } \\
\text { ess } \\
\text { Chest } \\
\text { pain } \\
\text { Fainti } \\
\text { ng }\end{array}$ & $\begin{array}{l}\text { Stop } \\
\text { the usage } \\
\text { of } \\
\text { caffine, } \\
\text { tobacco }\end{array}$ \\
\hline
\end{tabular}

Table 2: Classification on arrhythmia by ECG beat style

\section{B.Discrete wavelet Transform (DWT)}

This transform also widely used in signal processing. Signals were decomposed into both time and frequency representations. This provides good time resolution. DWT is carried out by repeated filtering of the input signal using two filters [15]. The DWT is formally written as Eq. (3)

$$
\mathrm{W}(\mathrm{a}, \mathrm{b})=\sum_{a} \sum_{b} x(b) e^{\frac{-a}{2}} \varphi\left(2^{-a} n-b\right)
$$

\subsection{Proposed Methodology}

Figure 2 depicts the block diagram of the proposed work flow.ECG signal from MIT-BIH database feed as input to the system. Further steps to be followed are Preprocessing, Feature Extraction and finally extracted data packets will be forwarded to cloud.

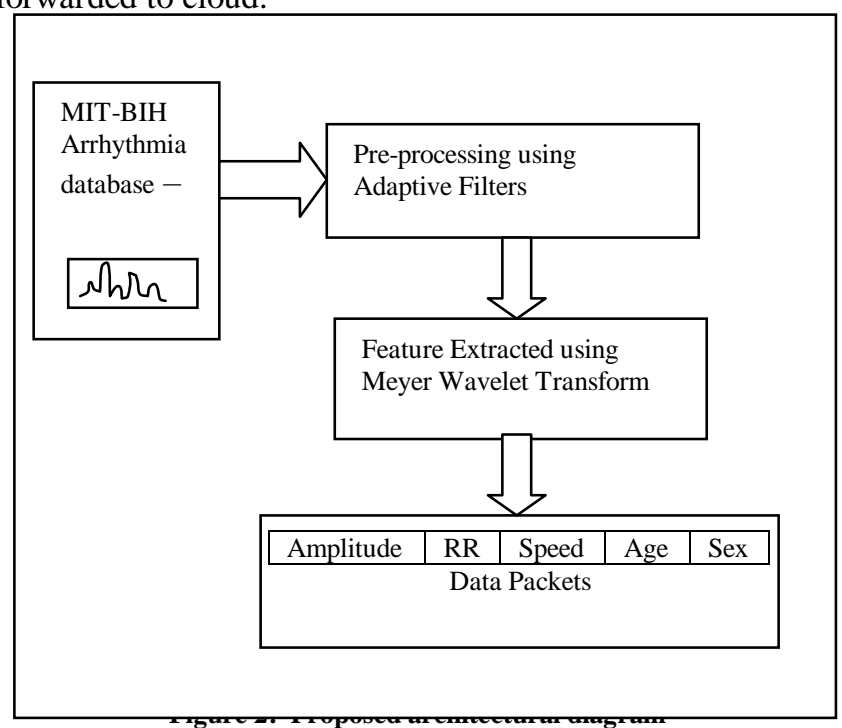

\subsection{Data Collection of ECG signals}

ECG signals for normal and abnormal patients of cardiac arrhythmia are collected for the process of mobile cloud offloading. The collection of data is the essential step of signal processing. In this work, MIT-BIH Arrhythmia database directory of ECG signals from physionet ATM BANK is used.The ECG Database in MIT-BIH Arrhythmia (mitdb) obtained from the Beth Israel Hospital Arrhythmia Laboratory is used as a data of ECG input signal for features extraction part processing [17]. These signals are further processed for removal of both noise and high frequency.

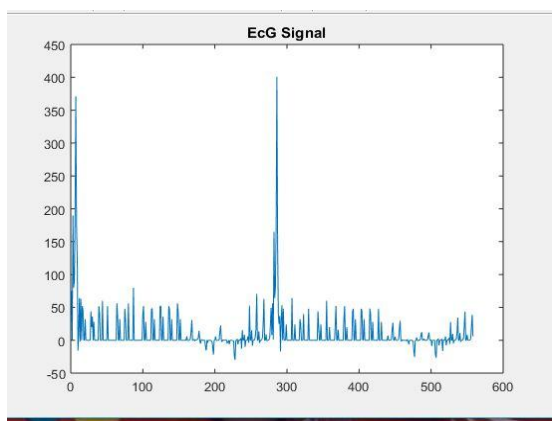

Figure 3:ECG Signal 


\subsection{ECG Signal Pre-processing}

Filtering ECG signal is the initial process of signal pre-processing. This is due to the reason that ECT signals are polluted with high frequency noise. Those unwanted noises are eradicated by applying band pass filter to remove the artifacts created by motion and baseline wander.

\subsection{Features Extraction using Meyer Wavelet Transform}

Meyer wavelet transform (MVT) is applied to solve the issue of non-stationary feature of ECG signals. The Meyer wavelet is an orthogonal wavelet introduced by Yves Meyer [12]. It is a kind of continuous wavelet and mainly used in multi-fault classification, fractal random fields and adaptive filters. This MVT is substantially differentiable with unlimited provision and well-defined in domain of frequency domain in terms as

$\psi(\mathrm{W})=\left\{\begin{array}{cc}\frac{1}{\sqrt{2 \pi}} \sin \left(\frac{\pi}{2} \gamma\left(\frac{a|w|}{2 \pi}-1\right)\right) e^{\frac{j w}{2}} & \text { if } \frac{2 \pi}{a}<|w|<\frac{4 \pi}{a} \\ \frac{1}{\sqrt{2 \pi}} \cos \left(\frac{\pi}{2} \gamma\left(\frac{a|w|}{4 \pi}-1\right)\right) e^{\frac{j w}{2}} & \text { if } \frac{4 \pi}{a}<|w|<\frac{8 \pi}{a} \\ 0 & \text { otherwise }\end{array}\right.$

$\gamma(x)=\left\{\begin{array}{cc}0 \quad \text { if } x<0 \\ x \quad \text { if } 0<x<1 \\ 1 \quad \text { if } x>1\end{array}\right.$

The reason to uses MVT wavelet is that it has additional beneficial features compared to the standard DWT and FFT wavelet transforms. Because it could automatically adjust to the different ECG signal features, by adapting large size window to look for long lived low frequency signals aspects and it uses small window to analyse the short time high frequency components.

\section{RESUlTS AND DisCUSSION}

This wavelet transform is used in ECG for decomposing the signal into various frequency scales where the characteristics waveforms are signified by Zero Crossings. The $\mathrm{R}$ peak is precisely discovered using MVT. In general ECG signal comprised of many data but for efficient energy consumption in mobile computing-based offloading the essential features are extracted using MVT with the aid of spectral analysis. These features alone characterize the behaviour of the ECG signals. And these information's are composed as data packets, to transfer in mobile adhoc network to the base station (Experts Location).
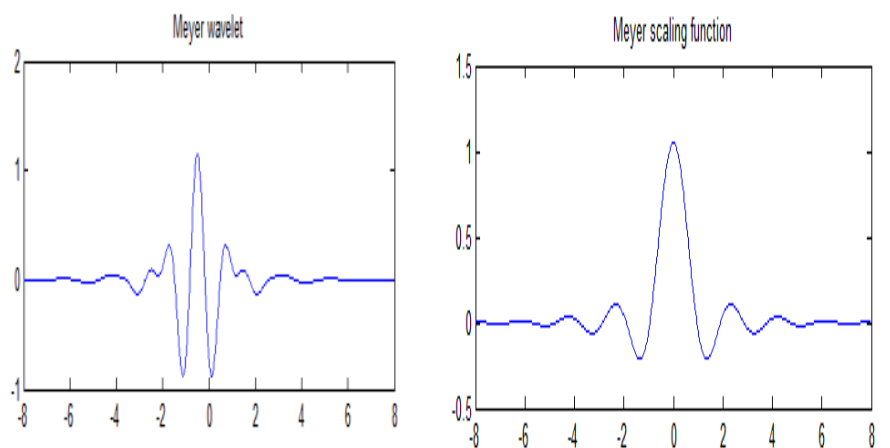

Figure 4: Meyer Wavelet Transform mother wavelet and its scaling function for feature extraction

ECG signals feed into MATLAB tool and features extracted.Further features send as data packets to cloud for further work. Below graph shows the Feature extraction output.
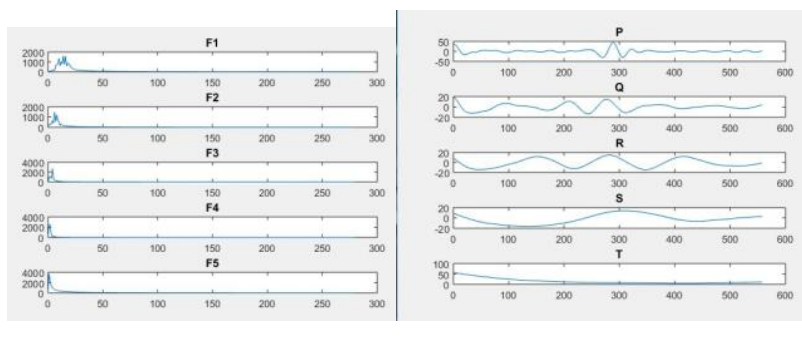

Figure 5: Feature Extracted graph

\section{CONCLUSION}

ECG is used by physicians to forecast and examine innumerable cardio vascular arrhythmias.Among several mobile applications this paper focus on the mobile healthcare applications to monitor the patient's ECG signals and if there are any abnormalities then its information is passed as the data packets over mobile network to the healthcare centers and physicians for diagnosis and appropriate treatment has to be taken at right time. This mobile cloud offloading greatly helps to extract ECG signal of a patient by pre-processing and significant feature like Amplitude, RR, Speed, Age, Sex and Medicine are extracted using Meyer Wavelet transform. Then transmitted as data packets over the mobile network and stored in cloud for future work which concentrated more on energy efficiency.

\section{REFERENCES}

[1] http://www.who.int/cardiovascular_diseases/en/

[2] Waechter J. 2012. Introduction to ECG's: Rhythm Analysis.www.teachingmedicine.com/pdf files/ECG Intro

[3] J. P. Carmo, and J. H. Correia, "RF CMOS Trasnsceiver at $2.4 \mathrm{GHz}$ in Wearables for Measuring the

Cardio- Respiratory Function", Elsevier, Vol. 44, 2011, pp.65-73.

[4] Sadiq, Ahmed T., and Nidhal H. Shukr. "Classification of Cardiac Arrhythmia using ID3 Classifier Based on Wavelet Transform." Iraqi Journal of Science 54, no. 5 (2013): 1167-1175.

[5] Acharya, U. Rajendra, Hamido Fujita, Oh Shu Lih, Yuki Hagiwara, Jen Hong Tan, and Muhammad Adam. "Automated detection of arrhythmias using different intervals of tachycardia ECG segments with convolutional neural network." Information sciences 405 (2017): 81-90.

[6] Saminu, Sani, NalanÖzkurt, and Ibrahim Abdullahi Karaye. "Wavelet feature extraction for ECG beat classification." In Adaptive Science \& Technology (ICAST), 2014 IEEE 6th International Conference on, pp. 1-6. IEEE, 2014

[7] Chen, Shanshan, Wei Hua, Zhi Li, Jian Li, and Xingjiao Gao. "Heartbeat classification using projected and dynamic features of ECG signal." Biomedical Signal Processing and Control 31 (2017): 165-173.

[8] Hamed, Ibrahim, and Mohamed I. Owis. "Automatic arrhythmia detection using support vector machine based on discrete wavelet transform." Journal of Medical Imaging and Health Informatics 6, no. 1 (2016): 204-209.

[9] Kiranyaz S, Ince T, Gabbouj M." Real-time patient-specific ECG classification by 1-D convolutional neural networks". IEEE Transactions 
on Biomedical Engineering. 2016 Mar;63(3):664-75.

[10] Apoorv Gautam and Maninder Kaur, "ECG Analysis using Continuous Wavelet Transforms (CWT)", IOSR Journal of Engineering, Apr.2012, Vol.2 (4), 632-635

[11] Rajiv Ranjan, V.K Giri, “A Unified Approach of ECG Signal Analysis”, International Journal of Soft Computing and Engineering (IJSCE), July 2012, Volume-2, Issue-3, 5-10.

[12] Shubham Vaish, Rajni “ Electrocardiograph (ECG) Signal Analysis for the Detection of Arrhythmia Abnormalities with Wavelets",International Journal of Computer Science and Network(IJCSN), Dec 2017

[13] Theis, Fabian J., and Anke Meyer-Bäse. Biomedical signal analysis: Contemporary methods and applications. MIT Press, 2010.

[14] Fatin A. ElhajNaomieSalimArief R. Harris Tan TianSweeTaqwa Ahmed "Arrhythmia Recognition and Classification using Combined Linear and Nonlinear Features of ECG Signals", Computer Methods and Programs in Biomedicine (2016).

[15] Srivastava VK, Prasad D. Dwt-Based Feature Extraction from ecg Signal. American Journal of Engineering Research. 2013;2:44-50.

[16] https://en.wikipedia.org/wiki/Wavelet

[17] https://physionet.org/cgi-bin/atm/ATM

\section{AUTHORS PROFILE}

SK. Piramu Preethika ${ }^{1}$ Research Scholar, Department of Computer Science, VISTAS.E-mail: preethikamanikandan@gmail.com

R. Gobinath ${ }^{2}$ Assistant Professor, Department of Computer Science, VISTAS, Chennai. 